REIMPRESIONES

Rev Chil Salud Pública 2013;

Vol 17 (2): 181-184

\title{
Atención médica en Chile
}

\author{
Healthcare in Chile
}

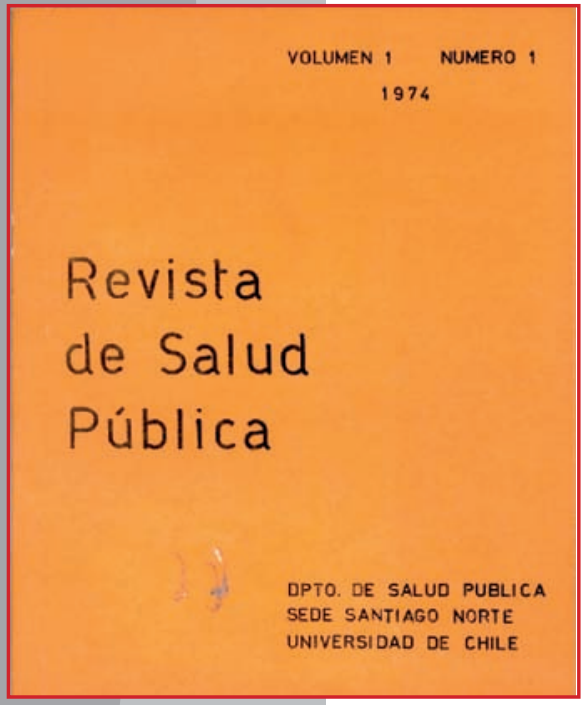

En el momento actual se dan condiciones muy favorables para organizar racionalmente la atención de salud de los chilenos. La integración del S.N.S. y del SERMENA en un cuerpo orgánico cuya cabeza rectora es el Ministerio de Salud abre posibilidades que no se dieron en el pasado. La tesis predominante, sin embargo, es el énfasis en la organización privada de libre competencia. Las ventajas que posee el sistema de mercado como elemento de regulación global de la economía ha llevado a sostener que un sistema similar, a través de la oferta y la demanda, regule los servicios de atención médica de los chilenos. No se advierte, empero, que en el campo de la salud chilena no se dan las condiciones indispensables para que opere un sistema de mercado existiendo, por otra parte, serios riesgos de deterioro en la situación de salud.

Un sistema de mercado competitivo funciona cuando existen muchos compradores y muchos vendedores, todos muy bien informados; cuando ninguno es tan importante para influir en los precios; cuando el sistema opera en forma independiente sin que se produzcan acuerdo en relación a los precios y cuando se permite la entrada libre al mercado de compradores y vendedores. Esto no ocurre en el campo de la atención de salud chilena. Como en todos los países en desarrollo hay escasez

\section{Ernesto Medina: En defensa del SNS. Una breve introducción}

En 1974 en el número 1 de la Revista de Salud Pública, el Director del Departamento de Salud Pública de la Sede Norte publicó el texto que presentamos en esta sección. No sabemos de la continuidad de esta Revista.

En este artículo el Dr. Medina defiende con valentía al SNS. Una publicación semejante en octubre de ese año, apareció en la sección signos del tiempo de la revista Mensaje. Artículo titulado Reestructuración del sector salud, firmado tímidamente por J.P.A. (¿Juan Pablo Arellano?), que comienza diciendo: "Una de las características centrales de programa económico que se está implementando consiste en la reducción del papel que le corresponde jugar al sector público".

El autor cita al general Leigh en la sesión inaugural de la convención de Consejos Regionales del Colegio Médico, en junio de 1974. En ella Leigh dijo: "al desarrollo de un sistema de seguros de salud que complemente o reemplace con eficiencia a una medicina curativa y que siendo financiado administrado por los propios beneficiarios permitan disminuir la carga del Estado en esta área".

\section{ERnesto Medina L.}

Director, Departamento de Salud Pública y Medicina Social Sede Santiago Norte, Universidad de Chile. (1974)
Evidentemente se trataba de un plan coherente y organizado para reducir el tamaño del Servicio Nacional de Salud. Leigh desplegó sus argumentos en esa ocasión:

"Es en mérito a todo lo anterior que se ha resuelto re-estructurar el sector Salud Fiscal; y proceder a convertirlo en un cuerpo orgánico único que tenga su cabeza rectora en el Ministerio del ramo, encargada de iniciar, supervigilar y evaluar las acciones encomendadas a las Instituciones ejecutivas descentralizadas.

"En este esquema, a las Direcciones Generales sólo les corresponderán funciones de coordinación y asesoría de las acciones que deban realizarse para el cumplimiento de las directivas. 
de vendedores de servicios por el número insuficiente de profesionales de salud que, en el caso de los médicos (1 por 1.5000 habitantes) representa la mitad del número que se requiere. Tanto el exceso de demanda (ej.: visita domiciliaria) como el exceso de oferta (ej.: alto número de cirujanos) no operan modificando los precios de las atenciones por cuanto se encuentran sometidos a un sistema de aranceles fijos. Por razones comprensibles en una medicina que mantiene elevados niveles éticos, que contrastan con los observados en otras partes del mundo, el Colegio Médico prohíbe y con razón la publicidad de los profesionales con lo cual no funciona el requisito de información de los eventuales compradores de servicios. Por razones justificadas, las universidades y nuestra legislación impiden la libre importación de profesionales extranjeros y regulan el número de los estudiantes que posteriormente ingresarán al mercado profesional.

A diferencia de otras actividades, las características y complejidades de la atención médica plantean situaciones muy particulares. En el campo de la atención hospitalaria, por ejemplo, hay importantes limitantes para el establecimiento de sistemas competitivos. En una ciudad de 60.000 habitantes, que requiere aproximadamente 300 camas de hospital, no hay ninguna justificación para construir dos hospitales competitivos de 150 camas cada uno en vez de uno solo de 300 camas que la experiencia muestra que es el tamaño en que se obtiene la mayor productividad.

Si se introduce a la salud en el campo libre de la oferta y la demanda excluyéndola del campo de las necesidades sociales surge una gama de impor- tantes consecuencias. El gasto en salud chileno (médico y farmacéutico), de acuerdo a las últimas informaciones disponibles, alcanza a algo más del $6 \%$ del producto geográfico bruto, o sea a unos 36 dólares o $E^{\circ} 35.000$ anuales por habitantes. De ellos aproximadamente $\mathrm{E}^{\mathrm{o}} 14.000$ van al sector público y los 21.000 restantes al sector privado en farmacia. Buena parte de las críticas que recibe la calidad de la atención en el Servicio Nacional de Salud dependen de la baja disponibilidad per capita para un servicio que, en las estimaciones más pesimistas atiende a algo más de la mitad de la población en sus necesidades de medicina curativa y a la totalidad de los chilenos para los importantes requerimientos preventivos, nutritivos y de fomento de la salud que han sido reafirmados como prioritarios en la política de salud actual.

Una disponibilidad anual por habitante de $\mathrm{E}^{\circ}$ 35.000 o su equivalente en dólares alcanza sólo a cubrir aproximadamente el costo de 2 consultas anuales y una semana de hospitalización por habitante. Como parece improbable que se pueda aumentar significativamente el $6 \%$ del producto nacional destinado a salud aparece un techo en el que la resultante lógica del proceso de libre oferta y demanda es el desplazamiento de los recursos humanos hacia los grupos de mayores recursos con ingreso que son justamente los que requieren más protección y asistencia médica.

Una política de este tipo parece poco recomendable si se recuerda que estos grupos, actualmente beneficiarios del S.N.S., corresponden a los brazos que mueven máquinas, herramientas, etc., y que posibilitan junto con el capital la creación de bienes y servicios. La falta de atención oportuna y eficaz en

"El Servicio Nacional de Salud y el Servicio Médico Nacional de Empleados darán paso así a organismos regionales de salud que tendrán independencia en su manejo presupuestario, técnico y administrativo, dentro de las normas dictadas por el Ministerio".

La reducción buscada del sector público se hacía bajo el apelativo de un estado siempre ineficiente, pero reconociendo las debilidades del sector privado:

"Al respecto, somos suficientemente realistas y pragmáticos para tener en claro que pese a todo el progreso que estamos seguros nuestra acción de Gobierno le dará a Chile en definitiva, existirán siempre sectores de chilenos que por una u otra causa deberán apoyarse en el Estado para ciertas prestaciones o servicios. Al mismo tiempo, vemos que a la fecha -y producto de los vicios heredados ya analizados- tanto la estructura privada de salud existente resulta totalmente insuficiente para cubrir las necesidades; como es de seria la limitación de recursos económicos de la mayor parte de la población para pagar estos sistemas".

"Por otra parte, sabemos que para el Estado - con su penuria actual- de recursos -le es y será absolutamente imposible financiar la atención de toda la población. Y que los servicios estatales nunca pueden llegar a ser realmente eficientes".

Con la publicación del texto de Ernesto Medina y con estas citas, quisiéramos alentar un estudio de las trastiendas de ese oscuro 1974, de los gestos que recomponen la lectura de las continuidades y rupturas en la historia de la micro-economización de la salud chilena y del rol de los salubristas en esas horas.

Esperamos que otros actores de esos tiempos nos hagan llegar documentos, de la misma talla que este producido por el entonces Director del Departamento de Salud Pública, que confirman que aun bajo las formas más totalitarias de la política, hay disidencia, controversia y debate. $\mathrm{O}$ de otro modo, que ni aun bajo una dictadura totalitaria, la salud pública deja de ser política. 
el campo médico implica significativos aumentos de costos de producción derivados del ausentismo que se produce como consecuencia de la ausencia o ineficiencia de la atención médica. Por otra parte, no es en absoluto indiferente la reacción que se crea en grupos que históricamente han dispuesto de atención médica desde 1924 y que, en el momento actual, han visto disminuir violentamente sus posibilidades de atención médica por el intensísimo desplazamiento de profesionales médicos y de colaboración desde el Servicio Nacional de Salud a instituciones privadas que les ofrecen mejores remuneraciones.

Para limitar los excesos de demanda hay ventaja en que la población no reciba atención enteramente gratuita y que contribuya al pago de su atención médica. Suele no recordarse que el sector obrero, atendido por el S.N.S., efectúa esta contribución que equivale a $6 \%$ del salario $(1 \%$ en el caso de los empleados acogidos al sistema SERMENA) y que el obrero que se hospitaliza se le descuenta un 30\% de su salario. A pesar de las altas tasas de aporte, el S.N.S. requiere un cuantioso aporte estatal para su financiamiento. Por lo demás, desde el punto de vista nacional es relativamente indiferente el origen de las contribuciones destinadas al pago de atenciones de salud: si se hacen recaer en las personas, ellas presionan por mejores salarios; si recaen en las empresas, ellas responden aumentando los costos y sí es el Estado se produce el alza de los impuestos. En definitiva, es la capacidad económica global del país la que financia los gastos de salud.

Resulta peligroso suponer que la panacea para mejorar la situación en salud sea acentuar más el significado del sector privado. Los sistemas competitivos organizados en cooperativas o en cualquier otra forma trabajan eficientemente cuando los recursos humanos y financieros disponibles para todos los grupos son suficientes pero no en situaciones como la chilena en que se requiere un proceso global de solidaridad nacional que marque con claridad qué grupos tienen prioridades en materia de atención de salud existiendo la obligación de suministrarla por cuanto ella no será satisfecha en el libre interjuego de oferta y demanda.

De lo que se trata en Chile es de definir con claridad qué grupos requieren asistencia organizada la que si no alcanza a ser financiada por los usuarios debe serlo por el Estado. Creemos que deben mantenerse en el plano de la medicina or- ganizada, no sujeta a presiones de oferta y demanda (a) los grupos de bajos ingresos; (b) los servicios materno infantiles, por cuanto además de la atención curativa requieren ingentes esfuerzos paralelos de prevención, educación y nutrición; (c) las actividades de prevención y fomento de salud, incluidas vacunaciones y planificación familiar; (d) la organización hospitalaria del S.N.S. que ha permitido el nivel que tiene la medicina chilena actual.

La mantención de estos servicios en el área organizada y con apoyo estatal no debe significar en modo alguno la mantención de las actuales estructuras del SNS y el sistema de remuneración por salario de los médicos. Implica procurar una efectiva descentralización regional y local y el local y el estímulo al mejor trabajo que puede obtenerse utilizando los sistemas de población a cargo (como en la situación inglesa) o la participación económica de acuerdo al rendimiento hospitalario.

Los excesos que, por razones políticas, se observaron en los servicios de salud durante la Unidad Popular no son razón suficiente para destruir sistemas de atención organizada que han demostrado eficiencia en la reducción de riesgo de muerte y en la mejoría de la expectativa de vida de los chilenos. En la misma forma que nadie ha propuesto devolver a manos privadas la industria del cobre, y los excesos observados en el área educacional no llevan a proponer la educación privada en reemplazo de la gratuita estatal, en igual forma, la utilización política de los servicios de salud o su costo inevitablemente alto no constituyen argumento suficiente para traspasar estos servicios de salud tan vitales como los productivos o educativos al área privada. Parece igualmente improbable que la Fuerzas Armadas que tienen excelentes servicios médicos financiados por el Estado los modifiquen o reemplacen por sistemas cooperativos o de medicina liberal.

El énfasis excesivo en el área privada de la medicina lleva a la producción de fenómenos indeseables en la solución de los problemas de salud del país: exageran la especialización y la super especialización; acentúa la concentración de los médicos en las grandes ciudades con abandono de los sectores rurales; determina un exceso de servicios en los grupos de mayor capacidad económica y un déficit en aquellos de menor ingreso 
que son justamente los que más lo necesitan.

La mayoría de los países del mundo ha aprendido la lección del elevado precio y poco rendimiento que en cuanto a salud tiene la medicina desorganizada y entregada a los deseos y posibilidades de los grupos más bien que organizada sobre la base de las necesidades nacionales que son las necesidades de todos. El ejemplo de EE.UU, país que aparece como arquetipo de soluciones basadas en el esfuerzo privado, es elocuente. El gobierno federal paga, en el momento actual, la mitad de las cuentas de hospitalización del país y financia el programa de atención médica gratuita de los mayores de 65 años (Medicare) los que representan un octavo de la población. Tiene a su cargo, también con carácter gratuito y financiado en consecuencia a base de impuestos federales, los servicios de atención a los veteranos (unos 15 mi- llones de personas) además de otros grupos como empleados federales, fuerzas armadas o reservaciones indígenas. Apoya, igualmente, con ingentes sumas de ayuda federal a los servicios organizados estatales y locales.

Todo lo anterior lleva a pensar que resulta peligroso establecer doctrinas globales en materia de atención de salud. La complejidad de los factores que intervienen y de los problemas que requieren solución no permite colocarse en posiciones dogmáticas aplicables a todos los campos de atención y a todas las necesidades.

Hay suficiente evidencia de que los niveles de salud observados en las provincias chilenas se asocian fundamentalmente con el nivel y volumen alcanzado por los servicios de medicina organizada. Constituiría un error muy serio proceder a su desmantelamiento. 